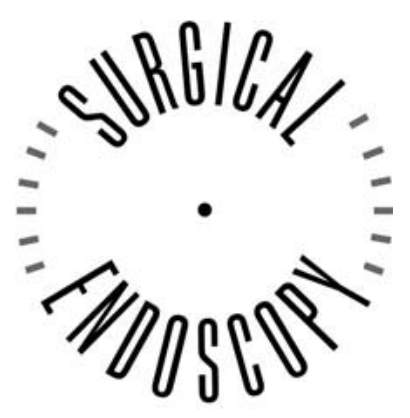

and Other Interventional Techniques

\title{
The suprapubic approach for laparoscopic appendectomy
}

\author{
O. Kollmar, K. Z'graggen, M. K. Schilling, B. M. Buchholz, M. W. Büchler
}

Department of Visceral and Transplantation Surgery, University of Bern Inselspital, 3010 Bern, Switzerland

Received: 7 February 2001/Accepted: 23 May 2001/ Online Publication: 4 December 2001

\begin{abstract}
Background: Because it produces superior cosmetic results, patients prefer laparoscopic appendectomy over open appendectomy. We developed two alternative laparoscopic routes of access to the abdominal cavity for appendectomy that use suprapubic incisions placed below the line of pubic hair. We then compared the results for these three different modes of access.

Methods: Operative characteristics, morbidity, outcome, and patient preference regarding three different approaches to laparoscopic appendectomy were compared in a retrospective study. In addition, a group of 24 healthy women were surveyed by questionnaire about their preferred technique and expected cosmetic results. Results: Between January 1997 and August 2000, 149 patients underwent laparoscopic appendectomy and were assigned to undergo one of the three techniques. Operative results, morbidity, and hospital stay were similar. Twenty-five percent of patients submitted to technique 1 (no suprapubic trocars) were satisfied with their method, vs $54 \%$ of patients with technique 2 (one suprapubic port, angled working trocars) and $100 \%$ of patients with technique 3 (two suprapubic parallel trocars). Almost all patients (92\% of those who had technique 1 and $100 \%$ of those who had techniques 2 and 3) chose the standard laparoscopic access as the cosmetically least attractive method. All of the healthy controls we interviewed preferred technique 3 .

Conclusion: The placement of suprapubic trocars improves the surgeon's working position during laparoscopic appendectomy. A laparoscopic approach using two suprapubic trocars yields the best cosmetic results in the opinion of the majority of patients and healthy interviewees.
\end{abstract}

Key words: Appendicitis - Appendectomy - Laparoscopy - Cosmetic results - Ergonomics

Correspondence to: $\mathrm{K}$. Z'graggen
Appendicitis is the second most common cause of acute abdominal pain requiring surgery $[21,25]$. Since laparoscopic appendectomy was first described by Kurt Semm [25], the technique has been modified several times [3, 16, 24, 25]. Eventhough laparoscopic appendectomy has failed to gain unequivocal acceptance among general surgeons, it is well accepted at most centers [14]. Arguments against the laparoscopic technique include higher costs due to the need for disposable equipment, a longer operating time, and a higher incidence of complications, including appendix stump insufficiency and intraabdominal fluid collections [7]. However, the technique can be performed safely [3], and it has the advantages of producing minimal surgical trauma and making it possible to explore, irrigate, and clean the entire abdominal cavity $[4,17]$. When a normal appendix is found, coexisting pathologies can be assessed [22]. Patients suffer less surgical trauma and thus require less analgesia during the postoperative course [20], they have an earlier passage of stool, and they resume normal activities earlier [6] with improved cosmetic results.

Laparoscopic appendectomy is most commonly performed through three ports. For special indications, one- or two-puncture techniques have been developed $[11,15]$, only occasionally does a fourth trocar need to be inserted. With standard technique, the video laparoscope is inserted through a periumbilical incision. Then a 12-mm port is placed through the left lower quadrant just lateral to the rectus muscle and a $5-\mathrm{mm}$ port is placed in the right lower quadrant (technique 1). We have developed two alternative methods to position the trocars (techniques 2 and 3). The goal was to improve the posture of the surgeon in ergonomic terms while at the same time producing better cosmetic results for the patients.

\section{Patients and methods}

Between January 1997 and August 2000, 169 patients with clinical suspicion of acute appendicitis underwent laparoscopic appendectomy, 
Table 1. Patient characteristics, operation time, and hospital stay according to operative technique

\begin{tabular}{|c|c|c|c|c|}
\hline & Technique 1 & Technique 2 & Technique 3 & Conversion $^{\mathrm{a}}$ \\
\hline No. of patients & 98 & 27 & 24 & 20 \\
\hline Female / male & $73 / 25$ & $19 / 8$ & $17 / 7$ & $13 / 7$ \\
\hline Age (yr) & $28.3 \pm 11.6$ & $30.0 \pm 10.2$ & $31.2 \pm 11.9$ & $43.3 \pm 18.5$ \\
\hline Operating time (min) & $62.4 \pm 23.9$ & $59.0 \pm 22.4$ & $48.1 \pm 17.0^{\mathrm{b}}$ & $121 \pm 48.3$ \\
\hline Hospital stay (d) & $3.7 \pm 1.5$ & $3.5 \pm 1.2$ & $3.8 \pm 1.6$ & $7.9 \pm 3.4^{\mathrm{c}}$ \\
\hline
\end{tabular}

${ }^{\text {a }}$ Patients undergoing conversion to an open procedure are listed as a separate group. They are not included in the statistical analysis

${ }^{\mathrm{b}} p$ 3D 0.018 (T3 vs T1) and $p$ 3D 0.013 (T3 vs T2)

${ }^{\mathrm{c}} p<0.001$ (T1-T3 vs conversion)

\section{technique 1}
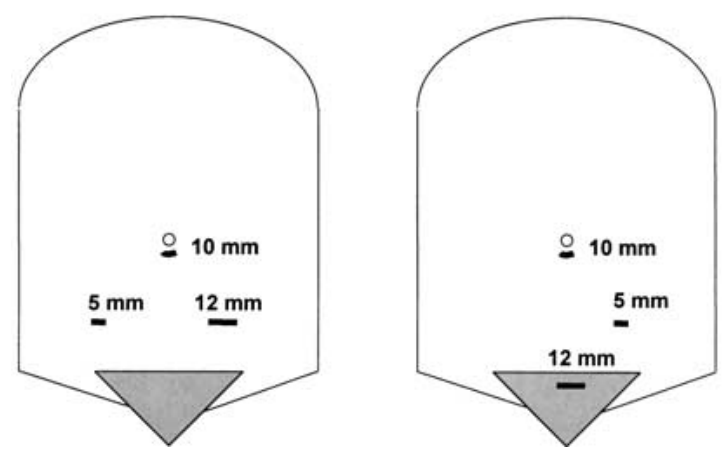

technique 3

technique 2

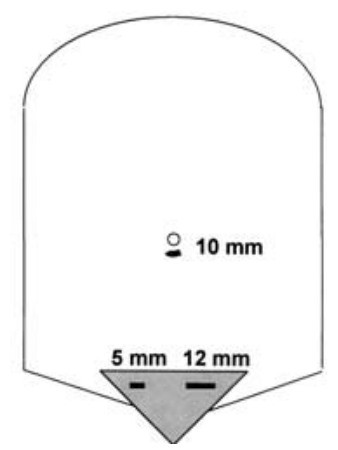

Fig. 1. Three different modes of access to the abdominal cavity (techniques 1,2 , and 3). which in our department is done primarily in women. Twenty of these procedures were converted to an open technique. The remaining 149 patients were assigned to undergo one of three techniques for laparoscopic appendectomy according to the surgeon's preference (Table 1). Each technique was performed by at least three different surgeons.

The data were then analyzed retrospectively. Operative characteristics, postoperative complications, outcome, and the patients' ratings of the cosmetic preferability of the three techniques of laparoscopic appendectomy were compared. Patients were followed with a questionnaire for long-term complications and to determine their opinions of the three. Questions concerning cosmetic outcome and preference of trocar placement were identical to those given to the control group. Since we perform laparoscopic appendectomy predominantly in younger women, a group of 24 healthy women (age range 18-30 years) was surveyed with a standardized questionnaire concerning cosmetic preferences only. The group consisted of study nurses. Two of the 24 had previously had an appendectomy - one by an open procedure and the other by the laparoscopic approach in another surgical department (technique 1). The same basic information on possible trocar locations without stating technical advantages/disadvantages was given to the interviewees by one of the authors. Questionnaires were then filled out individually and mailed to the corresponding author (techniques 1-3).

\section{Surgical technique}

The operations were carried out under general anesthesia. Pneumoperitoneum was induced by the Hasson technique through a periumbilical incision. After introduction of the video laparoscope, patients were placed in a Trendelenburg position, tilted to the left, and the epigastric vessels were identified. Two additional working trocars were introduced under laparoscopic control. Choice of positions for the working trocars (i.e., technique 1,2 , or 3 ) was by surgeon's preference (Fig. 1).

The appendix was skeletonized by bipolar coagulation or clips and transected with an Endo-GIA (Johnson \& Johnson, Cincinnati, OH, USA). It was then extracted with an Endo-Bag via the 12-mm operating port. In patients with a perityphlitic abscess or purulent fluid collec- tions, the abdominal cavity was rinsed and a drain was placed through the right incision for 1-3 days postoperatively. After removal of the instruments and desufflation of the pneumoperitoneum, the fascia below the umbilicus and the three small cutaneous incisions were closed.

\section{Statistical analysis}

Patient characteristics, operating time, hospital stay, postoperative complications, and patient outcome were recorded in a database and analyzed retrospectively. Patients were followed for long-term complications with a questionnaire. They were also evaluated to determine their overall satisfaction with the procedure and its cosmetic result.

Data are given as mean \pm standard deviation (SD) and analyzed using the Mann-Whitney U test. A $p$ value of $<0.05$ was considered statistically significant.

\section{Results}

A laparoscopic approach to appendectomy was possible in 149 patients $(88 \%)-109$ female $(73 \%)$ and 40 male $(27 \%)$ - with a mean age of $29.1 \pm 11.5$ years. Seventeen cases $(10 \%)$ were converted to open appendectomy and three $(2 \%)$ to a median laparotomy. Indications for the conversion to an open technique included perforated appendicitis with intraabdominal abscess (eight cases), an abscess in the psoas muscle, a carcinoid of the appendix, and a pseudomyxoma peritonei (one case each).

Patient characteristics are listed in Table 1. The operating time was shortest in group T3 $(48.1 \pm 17.0 \mathrm{~min})$ because one of the surgeons using technique 3 was particularly skilled and produced very low operation times. The difference in operation time for group T3 vs group 
Table 2. Etiologies of patients undergoing laparoscopic appendectomy

\begin{tabular}{|c|c|c|c|c|}
\hline $\begin{array}{l}\text { Postoperative and } \\
\text { histological diagnosis }\end{array}$ & Cases $(n, \%)$ & $\mathrm{T} 1$ & $\mathrm{~T} 2$ & $\mathrm{~T} 3$ \\
\hline Subacute appendicitis & $11(7)$ & 7 & 2 & 2 \\
\hline $\begin{array}{l}\text { Acute gangrenous } \\
\text { appendicitis }\end{array}$ & $74(50)$ & 47 & 13 & 14 \\
\hline $\begin{array}{l}\text { Perforated } \\
\text { appendicitis (partly with fibrino-purulent } \\
\text { peritonitis and/or perityphlitic changes) }\end{array}$ & $20(13)$ & 12 & 6 & 2 \\
\hline Other etiologies and normal appendix & $44(30)$ & 32 & 6 & 6 \\
\hline
\end{tabular}

Table 3. Morbidity and mortality after laparoscopic appendectomy

\begin{tabular}{llll}
\hline & Technique 1 & Technique 2 & Technique 3 \\
\hline $\begin{array}{l}\text { Morbidity } \\
\text { Wound infection }\end{array}$ & 4 & 1 & 1 \\
$\quad \begin{array}{l}\text { Hematoma of the } \\
\text { rectus muscle }\end{array}$ & - & 1 & - \\
Retrocecal haematoma & 1 & - & - \\
Retrocecal abscess & 1 & - & - \\
$\quad$ Intraabdominal abscess & 1 & $7.4 \%$ & $4.2 \%$ \\
Total morbidity & $7.1 \%$ & 0 & 0 \\
Mortality & 0 & & \\
\hline
\end{tabular}

Table 4. Cosmetic results and preference of technique in patients undergoing laparoscopic appendectomy and in healthy female controls

\begin{tabular}{lllll}
\hline & Technique 1 (T1) & Technique 2 (T2) & Technique 3 (T3) & Interviewed controls \\
\hline No. of patients & 98 & 27 & 24 & 24 \\
Female / male & $73 / 25$ & $19 / 8$ & $17 / 7$ & $24 / 0$ \\
Age (yr) & $28.3 \pm 11.6$ & $30.0 \pm 10.2$ & $31.2 \pm 11.9$ & 21.3 \\
Satisfaction with personal outcome & $93 \%$ & $93 \%$ & $96 \%$ & $100 \%$ \\
Preference for (own) method & $25 \%$ & $54 \%$ & $\mathrm{~T} 3(100 \%)$ & $\mathrm{T} 1(100 \%)$ \\
Cosmetically least attractive method & $\mathrm{T} 1(92 \%)$ & $\mathrm{T} 1(100 \%)$ & $(100 \%)$ & \\
\hline
\end{tabular}

T1 $(62.4 \pm 23.9 \min , p=0.018)$ and T3 vs group T2 $(59.0 \pm 22.4 \mathrm{~min}, p=0.013)$ was significant. The length of hospital stay did not differ among groups $\mathrm{T} 1, \mathrm{~T} 2$, and T3, but it was significantly longer in the group of patients who were converted to an open procedure $(p \pm 0.001)$.

The histological diagnosis (Table 2) included 11 cases (7\%) of subacute appendicitis; 74 cases $(50 \%)$ of acute gangrenous appendicitis, partly with fibrino-purulent peritonitis; 20 cases $(13 \%)$ of perforated appendicitis, partly with fibrino-purulent peritonitis and/or perityphlitic changes; and 44 cases $(30 \%)$ of normal appendix. Of these 44 patients, 22 (15\% of 149) had additional pathologies, including eight cases of adnexitis, one case of tuboovarian abscess, eight cases of ruptured ovarian cysts (one additional with endometriosis), and one case of endometriosis. Three patients had mesenteric lymphadenitis and one patient had sigmoid diverticulitis. In 11 patients with perforated appendicitis (Table 2) and one with a tubo-ovarian abscess, an abdominal drain was placed in the right iliac fossa and left for 1-3 days postoperatively. Drain volumes were 50-250 ml.

Ten patients $(7 \%)$ had suffered postoperative complications (Table 3 ), including three cases of wound infection and three cases of wound hematoma (five of these six complications occurred at the periumbilical incision), as well as one case of a hematoma of the right rectus muscle caused by a working trocar. Three patients $(2 \%)$ required relaparoscopy, with drainage of one retrocecal hematoma, one retrocecal abscess, and one intraabdominal abscess causing small bowel obstruction. Most of these complications were seen in group $\mathrm{T} 1$, but there was no significant difference in comparison with groups T2 and T3. Hospital mortality was nil.

Although overall satisfaction with the operation was high in all groups, the results of the follow-up questionnaire (Table 4) showed a significant difference among them in terms of the cosmetic result. Twenty-five of patients in group T1, 54\% of patients in group T2, and $100 \%$ of patients in group T3 preferred their own method and would recommend it to others. With few exceptions, patients $(92 \%$ in group $\mathrm{T} 1,100 \%$ in group $\mathrm{T} 2$, and $100 \%$ in group T3) found technique 1, which was the one most commonly performed, the least attractive. Moreover, $100 \%$ of healthy female interviewees preferred technique 3 and described technique 1 as the cosmetically least attractive method.

\section{Discussion}

One argument in favor of laparoscopic appendectomy is its use of several mini incisions for cosmetic reasons instead of a standard 3-5-cm McBurney access, which is sufficient in the presence of a normal appendix position. In cases where the appendix position is unusual, in obese 
3. Croce E, Olmi S, Azzola M, Russo R (1999) Laparoscopic appendectomy and minilaparoscopic approach: a retrospective review after 8-year's experience. Surg Laparosc Surg 3: 285-292

4. Cuschieri A (1997) Appendectomy: laparoscopic or open? Surg Endose 11: 319-320

5. Deutsch AA, Shani N, Reiss R (1983) Are some appendectomies unnecessary? An analysis of 319 white appendices. J R Coll Surg Edinb 28: $35-40$

6. Frazee RC, Roberts JW, Symmonds RE, Snyder SK, Hendricks JC, Smith RW, Custer MD, Harrison JB (1994) A prospective randomized trial comparing open versus laparoscopic appendectomy. Ann Surg 219: 725-728

7. Golub R, Siddiqui F, Pohl D (1998) Laparoscopic versus open appendectomy: a metaanalysis. J Am Coll Surg 186: 545-553

8. Hanna GB, Cuschieri A (1999) Influence of the optical axis-totarget view angle on endoscopic task performance. Surg Endosc 13: $371-375$

9. Hanna GB, Shimi S, Cuschieri A (1997) Optimal port locations for endoscopic intracorporeal knotting. Surg Endosc 11: 397-401

10. Hugh TB, Kelly MD, Li B (1992) Laparoscopic anatomy of the cystic artery. Am J Surg 163: 593-595

11. Inoue H, Takeshita K, Endo M (1994) Single-port laparoscopyassisted appendectomy under local pneumoperitoneum condition. Surg Endosc 8: 714-716

12. Klingler A, Henle KP, Beller S, Rechner J, Zerz A, Wetscher GJ, Szinicz G (1998) Laparoscopic appendectomy does not change the incidence of postoperative infectious complications. Am J Surg 175: 232-235

13. Lau WY, Fan ST, Yiu TF, Chu KW, Wong SH (1984) Negative findings at appendectomy. Am J Surg 148: 375-378

14. Memon MA (1997) Laparoscopic appendicectomy: current status. Ann R Coll Surg Engl 79: 393-402

15. Ng PC (1997) One-puncture laparoscopic appendectomy. Surg Laparosc Endosc 7: 22-24
16. Nowzaradan Y, Barnes JP (1993) Current techniques in laparoscopic appendectomy. Surg Laparosc Endosc 3: 470-476

17. Nowzaradan Y, Westmoreland J, McCarver CT, Harris RJ (1991) Laparoscopic appendectomy for acute appendicitis: indications and current use. J Laparoendosc Surg 1: 247-257

18. Olsen JB, Myren CJ, Haahr PE (1993) Randomized study of the value of laparoscopy before appendicectomy. Br J Surg 80: 922 923

19. Oppenheimer P, Weghorst S, Williams L, Ali A, Cain J, MacFarlane M, Sinanan M (2000) Laparoscopic surgical simulator and port placement study. Stud Health Technol Inform 70: 233-235

20. Ortega AE, Hunter JG, Peters JH, Swanstrom LL, Schirmer B (1995) A prospective, randomized comparison of laparoscopic appendectomy with open appendectomy. Am J Surg 169: 208212

21. Pier A, Gotz F, Bacher C, Ibald R (1993) Laparoscopic appendectomy. World J Surg 17: 29-33

22. Schirmer BD, Schmieg RE, Dix J, Edge SB, Hanks JB (1993) Laparoscopic versus traditional appendectomy for suspected appendicitis. Am J Surg 165: 670-675

23. Schreiber JH (1987) Early experience with laparoscopic appendectomy in women. Surg Endose 1: 211-216

24. Scott-Conner CE, Hall TJ, Anglin BL, Muakkassa FF (1992) Laparoscopic appendectomy: initial experience in a teaching program. Ann Surg 215: 660-667

25. Semm K (1983) Endoscopic appendectomy. Endoscopy 15: 59-64

26. Wagner M, Aronsky D, Tschudi J, Metzger A, Klaiber C (1996) Laparoscopic stapler appendectomy: a prospective study of 267 consecutive cases. Surg Endosc 10: 895-899

27. Welch NT, Hinder RA, Fitzgibbons RJ (1991) Laparoscopic incidental appendectomy. Surg Laparosc Endosc 1: 116-118

28. Zund M (1997) Status and outcome of laparoscopic appendectomy-results of a prospective study of 600 consecutive appendectomies. Ther Umsch 54: 505-509 